\title{
SMALL UNITE FOR EGYPTIAN COTTON HARVESTER.
}

\section{M.M.IBRAHIM [1], M.A.ALSHEKA [2] and M.S.ABDESALAM [3].}

\begin{abstract}
\end{abstract}
Cotton picking in Egypt is a major problem, where he still picking by hand it represents a large molecule of the production costs, so The present work is an attempt to design a machine to mechanization the process of Egyptian cotton picking to overcome the conditions of Egyptian agriculture, and the obstacles of physiological of Egyptian cotton varieties and farming methods. To overcome all these obstacles, and was bought to satisfy the need to develop and use new and important agricultural machinery technology. The aim of the present study was to develop, manufactured and quantifies the performance of a self-propelled mechanical cotton harvester. This harvester has main construction advantages., Firstly it is a self-propelled, it can control high, , it can control distance between rows and low damaged steams of plant. The developed cotton harvester was fabricated under the supervision of Agricultural.Engneer.Department, Mansoura University in private local workshops in Dekernes city, El_Dakahlia governorate and field tests at Ashmoon village. The performance effectiveness of the developed cotton harvester. Best results were obtained when using forward speed approaching to $0.36 \mathrm{~m} / \mathrm{s}$ with a modified form of plant density the efficiency of picking about $70 \%$ at the machine performance rate almost 3.5 hours per faddan that when using 4 units for picking 2 rows at same time. Also getting less yield loss when using only two units to harvest a single row. Thus can access the best methods for mechanization the harvesting of Egyptian cotton. In other way can improve harvest efficiency from $70 \%$ to $97 \%$, by re-picking three times or more.

[1]Prof. of Agric. Eng. Dept. of Agricultural Engineering Mansoura university. [2]Prof. of Agric. Eng. Dept. of Agricultural Engineering Mansoura university. [3]Ph.D. Researcher in Agricultural Engineer. Faculty Of Agriculture Mansoura university. 


\section{INTRODUCTION}

otton crop in Egypt have a privileged position according to others field crops. Cotton plant is considered the backbone of the Egyptian international income. The cultivated area in Egypt since 2013 is about "250000 feddan "(Abdel-mageed.,2013)., it is one of the important manufacturing and export crops, the hair cotton is used in textile industry, and cotton seed is one of the important sources of oils and residues used in the manufacture of animal feed. In the past Cotton crop in Egypt it is the first export crop because Egyptian cotton known in foreign markets is the best in outstanding qualities in terms of the length of a staple, durability, and softness, and homogeneity. From here, the researchers make great effort to promote the crop productivity through the development of new varieties distinct in technical qualities and Have a high producing capacity, and every variety fits the region area, which implant, in addition their efforts to supply farmers in the most appropriate agronomic for each variety separately to get the highest producing. However, researchers in Egypt make a Little effort to development the cotton harvest methods and, process after harvest like cleaning. However, in the last 15 years happened a gradual deterioration in the productivity, that was happened by many reasons, the most important reasons is the high of production costs and the marketing problems of the crop. Today all cotton producers in the world uses mechanical harvester, but hand picking uses in a very small rang because of its Primitive and not properly to modern producing. Cotton picking is a major problem in cotton production in Egypt, where he still picking by hand it represents a large molecule of the production costs it up to $40 \%$ (Abdel-mageed.,2010). Mechanical harvest of cotton is a relatively new concept with little more than 100 years lapsing from the time the first cotton-harvesting machine was developed until it almost entirely replaced manual harvesting. "Cotton harvest machines widely used in the United States fall into two categories: picker or stripper pickers and strippers The first patent for a mechanical cotton picker was granted to S.S. Rembert and J. Prescott of Memphis, obtained a patent on a spindle that provided the basic principle for the barbed-spindle widely used on modern-day "(Crawford., 1981). "Efforts to develop mechanical 
harvesters had been ongoing since about 1850, and functional models of spindle pickers and strippers were available by the 1920s and 1930s "(Crawford et al., 2009). "Cotton pickers, also known as spindle machines, use prongs to push into the cotton bolls and then twist to cleanly remove the cotton, leaving behind the burr attached to the stem. The machine has doffers -- metal bars or cylinders with teeth that pull the cotton from the prongs and drop it into the machine's conveyor system, which then uses air to transport the cotton into a basket" (Willcutt et al., 2010). "Cotton pickers and strippers use an air conveyor system, coupled with a basket and trailers for transport. In recent decades, cotton strippers have come equipped with a mechanism for removing the excess stems and other debris. low cotton prices, abundant hand labor ,harvest losses with the machines, inadequate gin cleaning equipment, and lack of effective harvest aids (primarily desiccants) delayed their widespread acceptance"(Kirk et aI., 1964). "The first pickers were only capable of harvesting one row of cotton at a time, but were still able to replace up to forty hand laborers The current cotton picker is a self-propelled machine that removes cotton lint and seed (seed-cotton) from the plant at up to six rows at a time. There are two types of pickers in use today" Snyder and Blackwood (1977).

\section{MATERIALS AND METHODS}

The aim of the present study was to develop, manufactured and quantifies the performance of a self-propelled cotton harvester. The main problem of mechanical picking of Egyptian cotton in the physiological characteristics especially about large volume, height of plant, and branching density. In addition, the conditions of Egyptian agriculture like small agricultural holding, sporadic fields, and narrow roads between fields that not prepared to huge machines that are used across the world. In addition, weak economies of Egyptian farmers that harvester. In an attempt to design a machine to mechanization of process Egyptian cotton picking to overcome the conditions of Egyptian agriculture, and the obstacles of physiological of Egyptian cotton varieties and farming methods . To overcome all these obstacles, we put some conditions to reach a solution to these problems of Egyptian cotton picking. 
Basic conditions must be in the appropriate machine to harvest Egyptian cotton.

1 -Low of costs to fit the weak economics of Egyptian farmers. 2 - Not to damage the growing plants to can get more than one crop picks 3 -Maintaining the picked crop cleanliness to get a high cotton rank. 4 -Easy of process, grading and sorting this relates of the picked cotton. The objective of present work creating some ideas to try resolving the mechanizations problems of Egyptian cotton picking, and testing these ideas to know how it cans success, and design tools and mechanisms that help it. This ideas summarize about designing system using means for taking cotton fibers from bolls and transmit it by air suction, this system designed on a self-propelled machine, this system should have some conditions to success.

1- Machine design is capable to adjusting heights to face different heights of Egyptian cotton Varieties.

2- Machine design is capable of adjusting width and interior dimensions to facing the different distances between the rows of planets.

3- The machine should be small size and easy to move and transmit to can access to the fields about a crossing narrow roads and can rotation in the field ends.

4- The machine should have a big role in reducing the harvest costs.

5 - Design of machine should easy in operation and maintenance.

6- The economics of using this design should significantly better than hand picking in terms of the qualities and characteristics of cotton captured and their impact on the crop rank.

\section{Materials}

(Designing and manufacturing a self-propelled machine with cylindrical thorn matrix) The machinery components and materials used in present investigation may be indicated as follows: in Fig (1)

When studying the available possibilities, that can help to start project. Was found an gasoline internal combustion engine (13 HP at 3600 RPM) provided with gearbox and connected with two wheels can obtain three forward speeds and one backward speed and one speed to PTO. From here the research plan need to using this engine and create design derives power from this engine. 


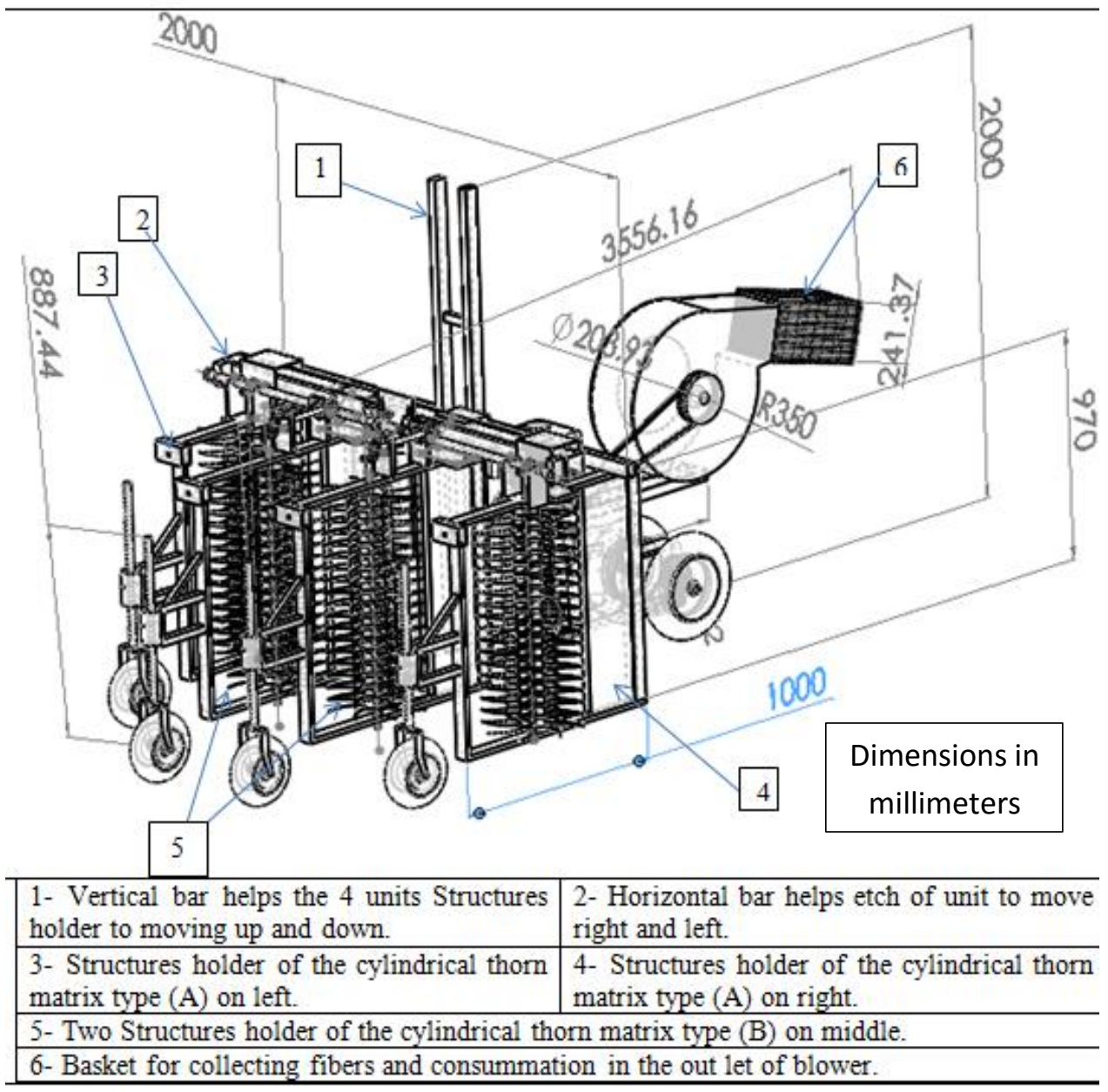

Figure 1: Prospective of the machine design in forward view.

These design Based on a bended metal Thorns spin in planets row direction shown in Fig (2) these thorns are flexible to return after bending. When thorns rotate speedily, can clashing the cotton fibers and a Little of Contaminants. These thorns are in a vertical cylindrical matrix was Install on a metal Structures, these designed to allows one of planets row can passing between two units of rotate cylindrical thorn matrix., the cotton fibers removed the thorns by suction air force and transmitted to backing in a basket. 


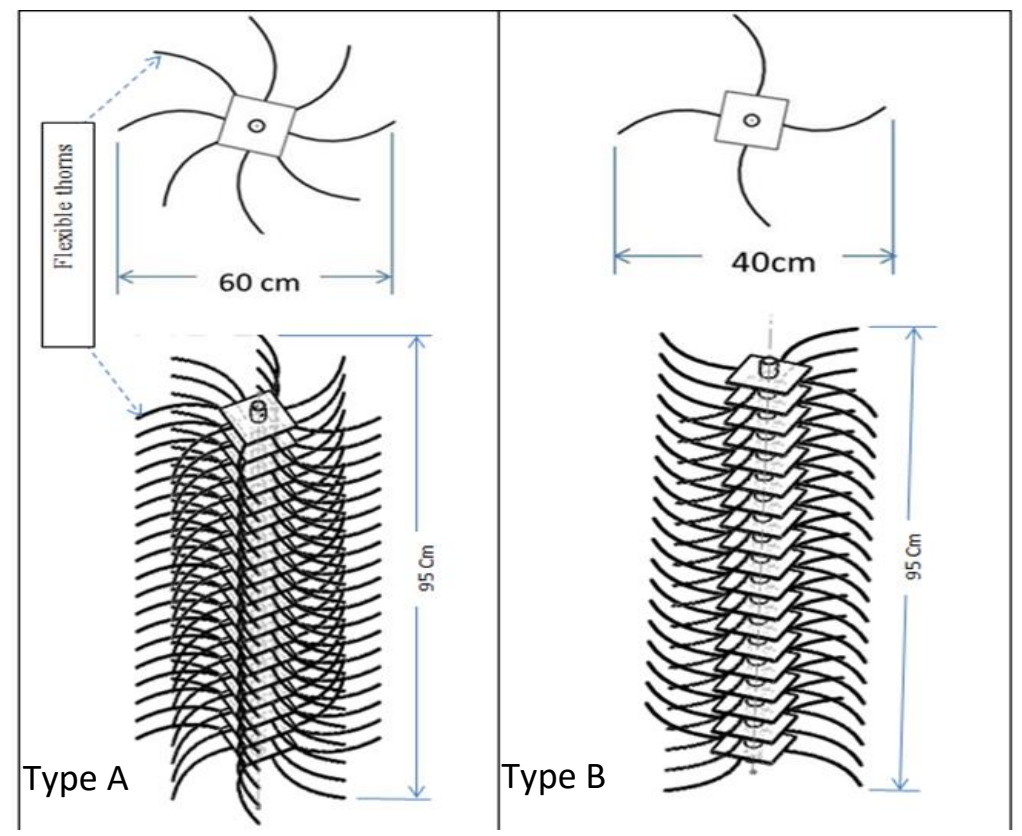

Figure 2: Types of thorn matrix

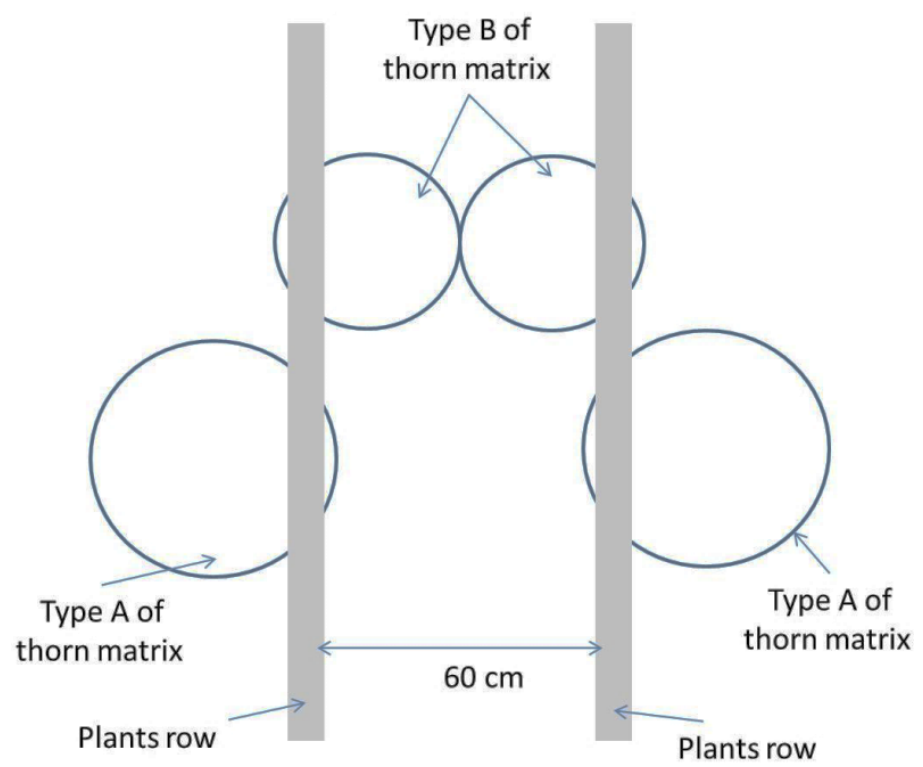

Figure 3: Explains how the two types of thorn matrix dealing with plants rows. 


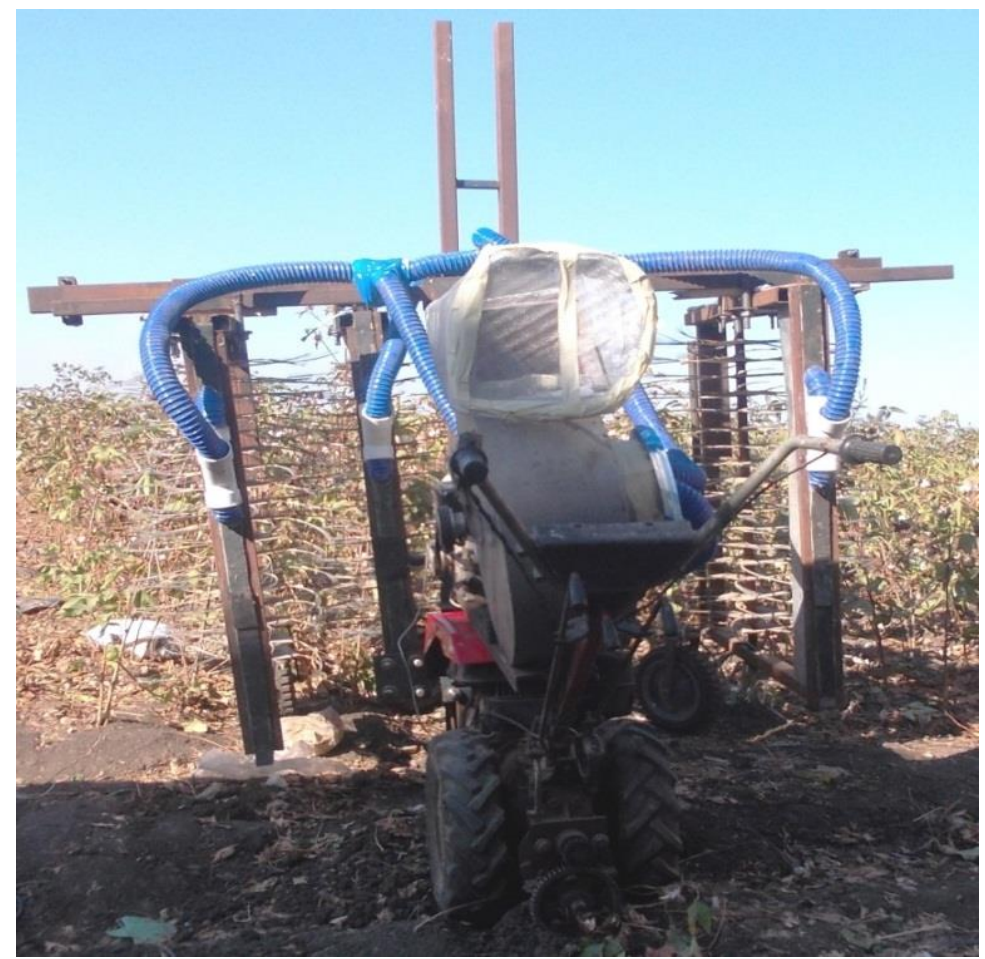

Figure 4: Installation of all components of machine at field.

The air suction system composed of an internal combustion engine have (6.5 HP) and a big blower its diameter $(60 \mathrm{~cm})$. The rotate power transmits between engine and blower by thong equipped with means to control the strain of the throng, which can control the rotate speed of blower fan. Also can control of rotate speed by the fuel valve of the engine.

\section{Methods}

The developed of the present two cotton harvesters aids was fabricated under the supervision of Agric.Eng.Department, Mansoura University in private local workshops in Dekernes city,El_Dakahlia governorate and field tests at Ashmoon village. The machine waking by crossing etch planet row between two units of (cylindrical thorn matrix).

The rotate speed: of the cylindrical thorn was measured by tachometer electronic circle (RPM meter) (round per minute electronic circle meter). 
The picking efficiency: calculated by the ratio between the number picked bolls and total bolls (picked and remains) as follow:

Picking efficiency $=\frac{\text { count } \text { of pickedopened bolls }}{\text { total of opened bolls }}$

The efficiency of cotton cleaning: measured by weighing the cotton samples after cleaning and weighing the pollutions. The weighting done by a digital balance with $0.005 \mathrm{~kg}$ measurement accuracy as follow:

Cleanness efficiency $=\frac{\text { weight of cleaned cotton }}{\text { total cotton weight }}$

In experiments should calculate the efficiency, productivity, losses, pollution in the picked crop, and damaged to know how the present investigation can helps of solving the cotton harvesting problems in Egypt and can compare it with the foreign methods of cotton harvesting. Machine productivity $=\frac{(\text { forward speed }) *(\text { work width }) *(\text { efficiency })}{(\text { Area unit })}$

In present investigation should test (the fabricated self-propelled machine), and know the appropriate ways of using the aids, and should make a comparing between the present aid of cotton picking and the hand picking. In other way make another comparing between other past machines and present two aids, these comparing in efficiency, losses, plants damaged, and operation costing. In other side test the effect of using (the fabricated self-propelled machine) in the cleanliness of the picked crop to get a high rank for cotton and know the damage that may happen to growing plants.

\section{RESULTS AND DISCUSSIONS}

1- The effect of rotary speed of cylindrical thorn with forward movement about $0.36 \mathrm{~m} / \mathrm{s}$ and $0.7 \mathrm{~m} / \mathrm{s}$ on picking efficiency and cleaning efficiency. In Fig (5) and Fig (6). The efficiency of picking calculated by counting the open bolls remains after machine crossing in a known distance and compare it with the total of bolls in a same distance, The efficiency was 
increased when increased the rotary speed of cylindrical thorn matrix because Probability of Collision between bolls and thorns was increased.

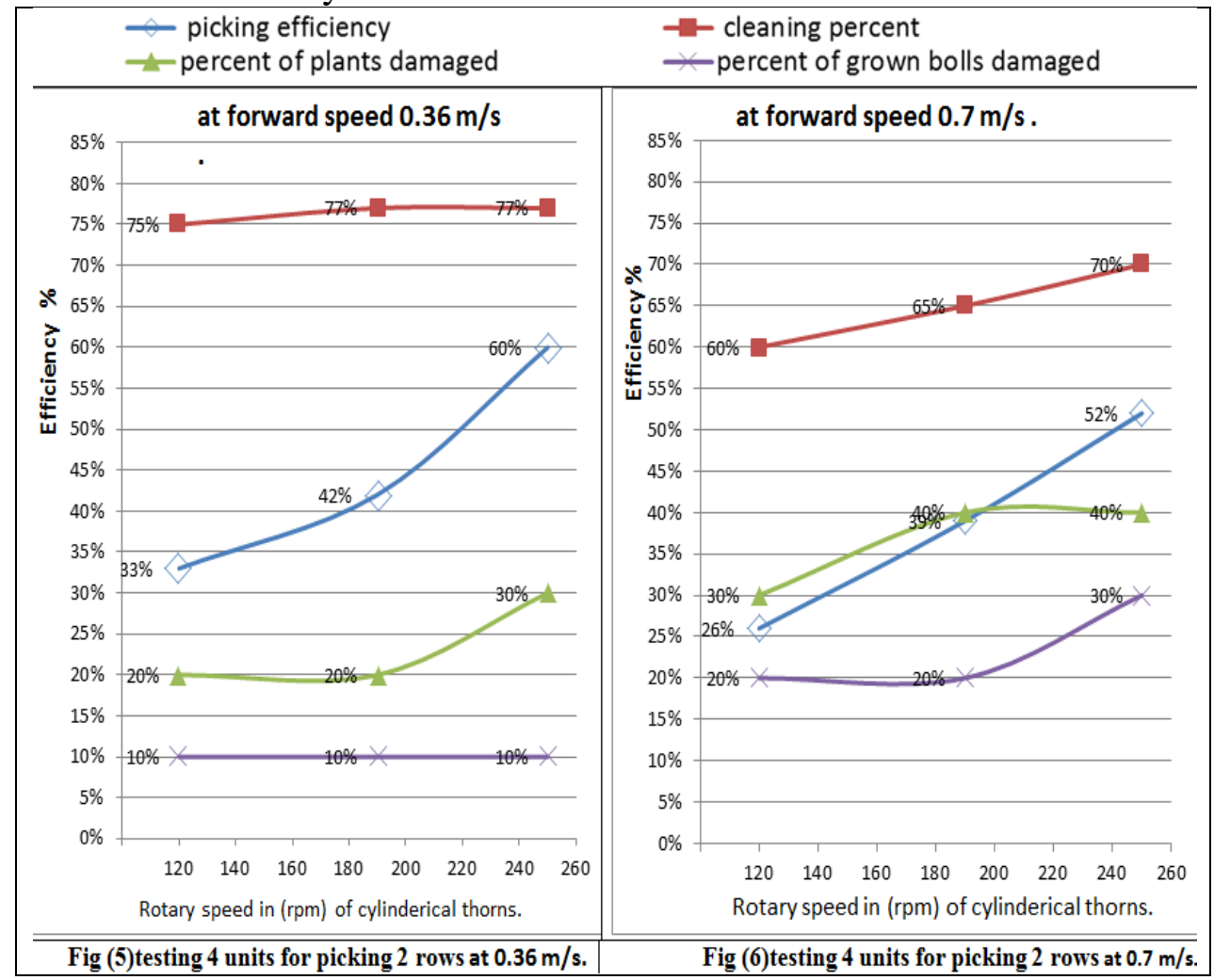

The cleanliness of the picked crop in logically reduced when increased the rotary speed of thorns because Probability of Collision increased between crust, leaves and plant branches. But the cleanliness calculated by weight quantities picked of cotton and pollutions and win increased the rotate speed the also quantities picked of cotton increased, so the pollutions percent reduced. The main reason of planets damaged is the narrow distance between rows and big branches that courses difficulty of machine unites crossing between rows. When need to tack two or three picks of crop harvest, have to preserve the growing planets and bolls to the next harvest. The damaged percent known by counting the number of bolls and planet damaged after machine crossing, in known distance can reduce damaged by updating planet density form. When need to increase 
productivity should increase forward speed, In Fig (6) explain that more forward speed means little chances clash between thorns and cotton fibers on bolls, but the planet density not help for that so the planet damaged increased ,also the machine engine have more strength and stopped many times. if machine redesigned to depended on a big engine and choosing best ways for agriculture to have an appropriate planet density that may help for more efficiency and productivity.

2. Testing the self-propelled machine 4 units for picking 2 rows when updating the planet form. with forward movement about $0.36 \mathrm{~m} / \mathrm{s}$ and 0.7 $\mathrm{m} / \mathrm{s}$. In fig (7)the updating the planet form to proportion of the mechanization picking that do by cut the big branches of planet. These branches extended on area between rows and resist the rotation of thorns and resist the forward movement of machine.

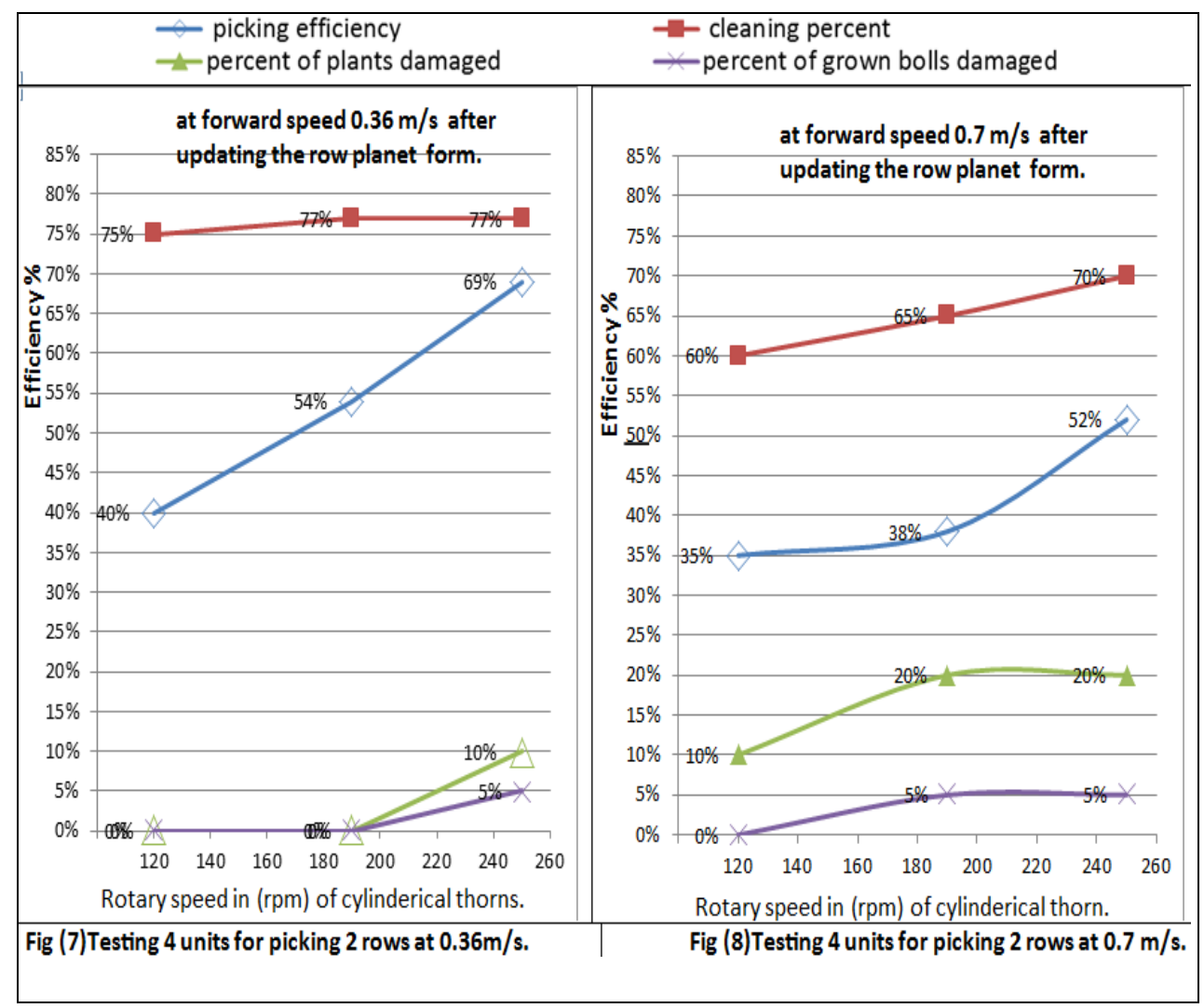


Comparing with Fig (5) can show improvement of efficiency in same rotate speeds. That observed by little of open bolls remain behind machine. These can explain the Effect of planet Breeding can helps in successfully of mechanization picking. In Fig (7) Shown the plant damaged reduces in comparing with Fig (5). The damaged was reduced because the planet density form help machine for little crashes with plant branches and easy passing between rows. The updating of planet form to proportion the mechanization picking helps machine units to easy passing between rows in forward speed $0.7 \mathrm{~m} / \mathrm{s}$. but also little chances clash between thorns and cotton fibers on bolls . In comparing with Fig (7) when increase the forward speed, have more losses of unpicked bolls, so if need to increase the field capacity, must improving the (rpm) of cylindrical thorn and the air suction force, this needed to use more horse power and use big engine. In Fig (8) and same figures not helps enough for completely save planet because of the narrow distance between rows, but the appropriate distance for machination picking about 70 to $90 \mathrm{~cm}$.

3. Testing the self-propelled machine 2 units for picking one rows when updating the planet form with forward speed $0.36 \mathrm{~m} / \mathrm{s}$.

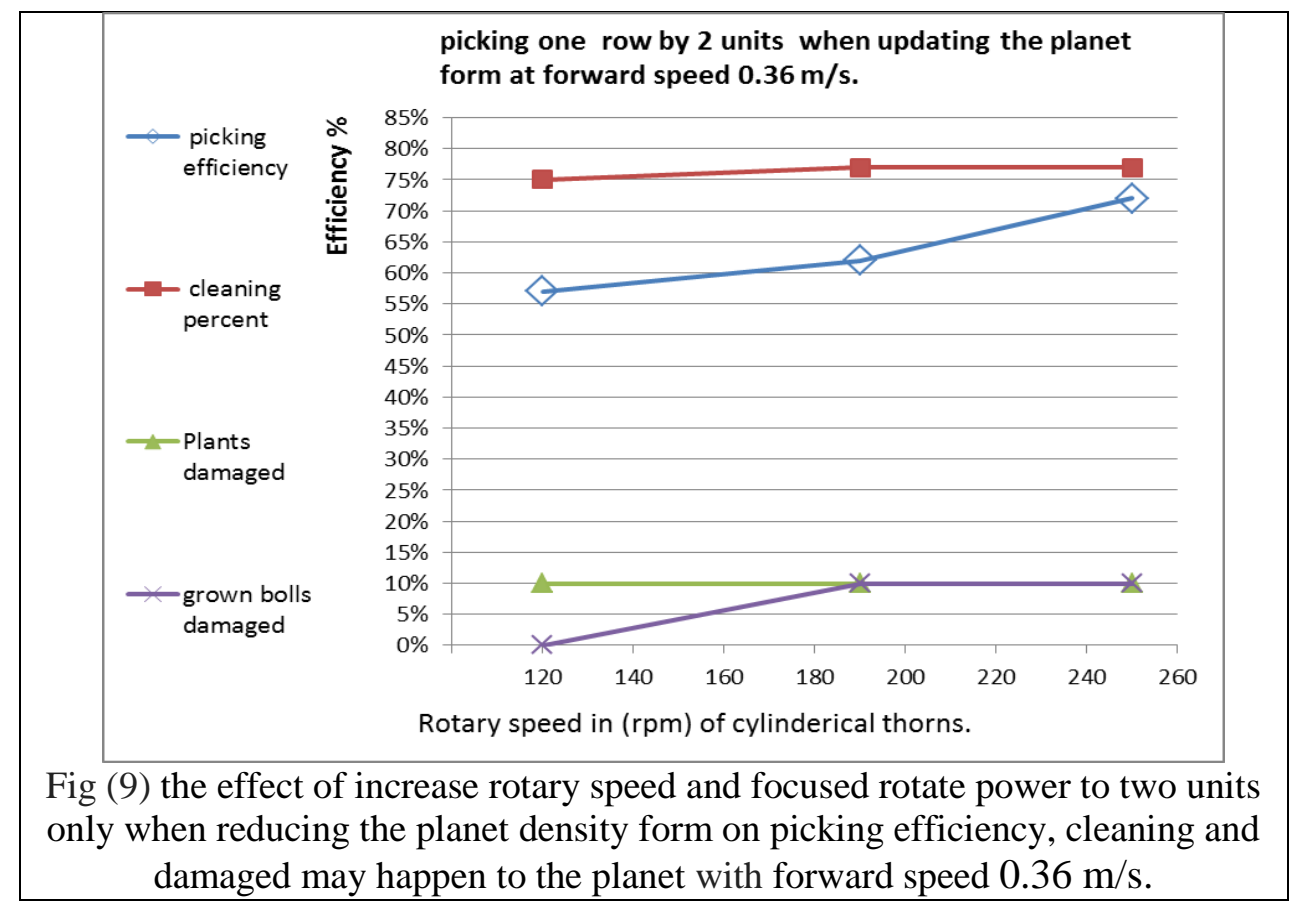


The main reason of this test is reduce stress of the engine of the machine to give more power to cylindrical thorns rotation. In Fig (9) shown the best efficiency than the other testes but low productivity to halve, because the dealing with one row at once. This test proves the success the idea of rotary cylindrical thorns matrix, but need to create the appropriate conditions of agricultures and Manufacturing of this design to improve machine performance.

\section{REFERENCES}

Abdel-mageed, Mohammed.(2010). Director of Cotton Research Institute, Ministry of Agriculture, www. Youm7.com/bookmark.php?v=20), 2/mars/2010.

Abdel-mageed, Mohammed.(2013). Chairman of the Supreme Council of Egyptian Cotton, elmasry elyom journal, 26/5/2013.

Crawford, S. H. (1981). Accelerating cotton boll opening with foliar treatments.Louisiana Agriculture, 25(1), 12-13.

Crawford, S. H; R. B. Leonard, and K. R. Carroll. (2009). Cotton response to timings of harvest aid treatment. Proceedings of the Cotton Physiology Conference,41,82.

Kirk, I. w., E. B. Hudspeth, Jr., and D. E. Wanjura. (1964). A broadcast and narrow row cotton harvester. Texas Agricultural Experiment Station Progress Report (No. 2311, May 7). College Station: Agricultural Communications, The Texas A\&M University System Agriculture Program.

Snyder. J. W.andT. R. Blackwood,(1977). Source Assessment: Mechanical Harvesting Of Cotton - State Of The Art, EPA-600/2- 
77-107d, U. S. Environmental Protection Agency, Cincinnati, OH, July 1977.

Willcutt,M.H.; M.J. Buschermohle.; G.W. Huitink.; E.M. Barnes.; J.D. wanjura. and S.W. Searcy.,(2010). Mississippi State University., University of Tennessee Knoxville , University of Arkansas (retired) Little Rock, Arkansas, Cotton Incorporated Cary, North Carolina, USDA-ARS Lubbock, Texas, Texas A\&M University College Station, Texas The Spindle-Type Cotton harvester.pdf.

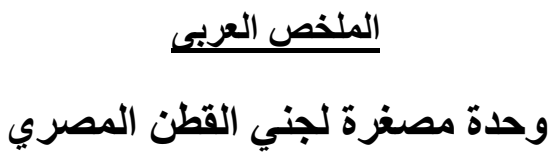

أ.د/ماهر محمد إبراهيم (')، أ.د/محمد أحمد الثيخة (") و م/ محمد صلاح عبد السلام(") يشكل جني القطن مشكلة كبيرة وقد يصل الي • ؛\% من تكاليف الإنتاج نظر الارتفاع أجور

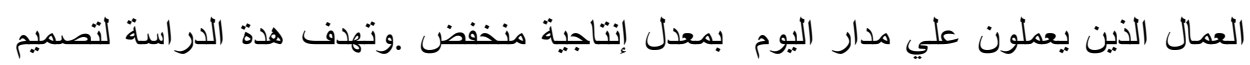

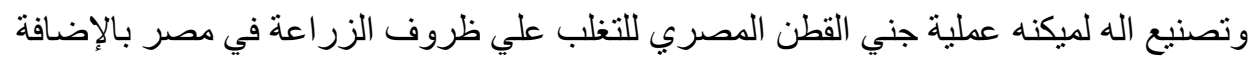
إلى المعوقات الفيسيولوجية لأصناف القطن المصري وطرق الزراعة التي لا تناسب عمليات

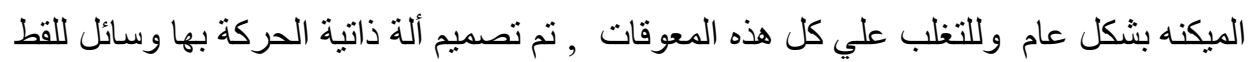

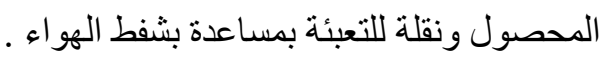
و أثناء تصميم الالة تم مراعاه أن تكون قابلة لتعديل ارتفاعها لمواجه الارتفاعات المختلفة

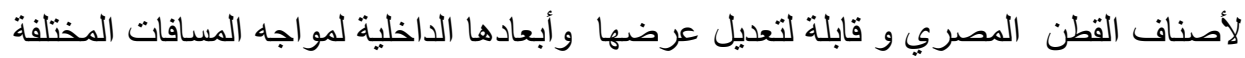
بين صفوف الزراعة و أن تكون الالة صغيرة الحجم وسهلة النقل لتمكين وصولها إلى الحقول

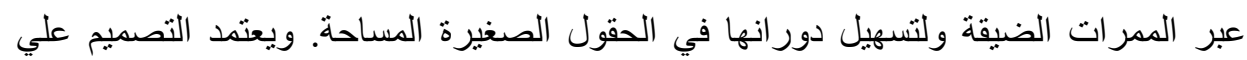
ريش معدنية دوارة منحنية في عكس اتجاه المحصول وهي مرنة بحيث ترتد بعد انحنائها و عند

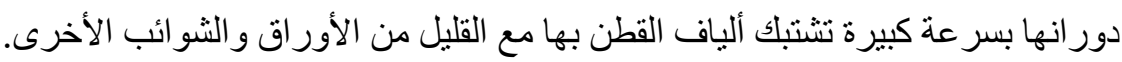

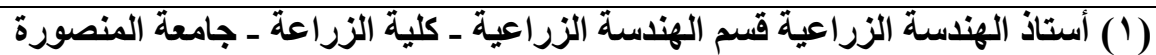

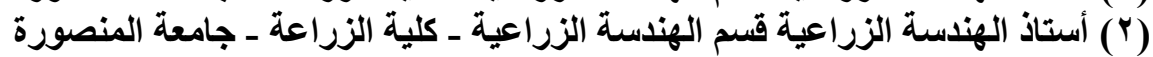

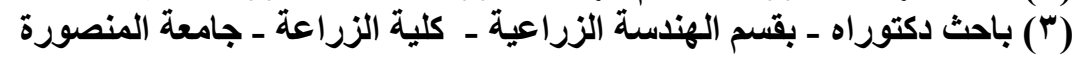


هذه الريش مثبتة علي هياكل معدنية وتكون علي شكل مصفوفة رأسية (أسطو انة دوارة) بحيث

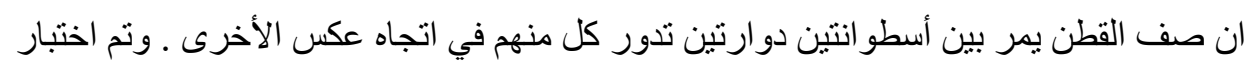
الالة عند سرعتين أماميتين وقياس كلا من (كفاءة الجني-نظافة المحصول-مستوي الضرك الضرد

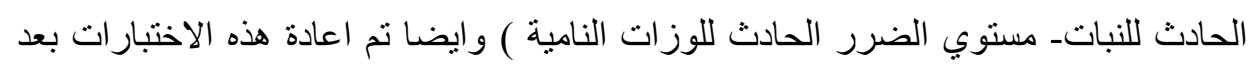

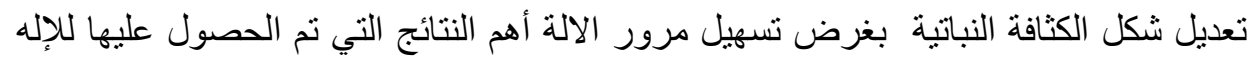

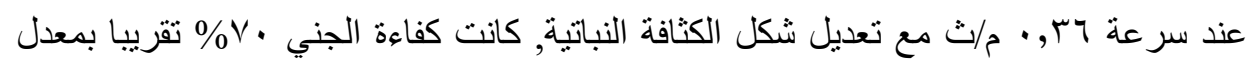

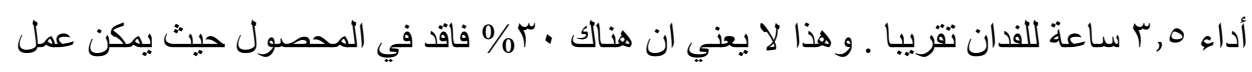

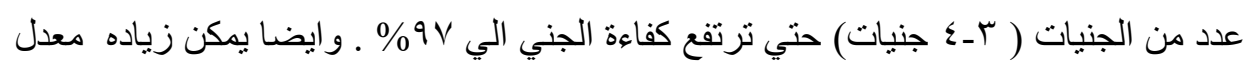
الاداء عن طريق زيادة عدد الوحدات المستخدمة للجني. 